\title{
Konstruksi Bounding Volume Hierarchy dengan Metode Agglomerative Clustering untuk Meningkatkan Performa Ray Tracing
}

\author{
Arif Fathur Mahmuda, Anny Yuniarti, dan Wijayanti Nurul K. \\ Jurusan Teknik Informatika, Fakultas Teknologi Informasi, Institut Teknologi Sepuluh Nopember (ITS) \\ Jl. Arief Rahman Hakim, Surabaya 60111 Indonesia \\ e-mail:afmahmuda@gmail.com, ayuniarti@gmail.com,wijay.cs@gmail.com
}

\begin{abstract}
Abstrak-Ray Tracing sebagai algoritma rendering yang menghasilkan citra realistis memiliki beberapa kekurangan. Salah satu di antaranya adalah perhitungan persilangan rayobject pada tiap pixel yang memakan $75 \%$ waktu dari keseluruhan proses rendering. Penelitian ini menerapkan metode yang diharapkan dapat mempersingkat proses perhitungan persilangan ray-object dengan membangun struktur data berupa binary tree. Tree yang dibangun sering juga disebut sebagai Bounding Volume Hierarchy (BVH) di mana masing-masing node-nya adalah sebuah container. Struktur data tersebut akan dibangun dengan metode Approximate Agglomerative Clustering (AAC) yang merupakan metode bottom-up clustering dengan topdown preprocessing. Metode AAC dengan parameter yang baik dapat meningkatkan performa Ray Tracing. Metode-metode yang diterapkan sangat mudah diparalelkan sehingga performa algoritma meningkat jika dijalankan pada lingkungan paralel. Hasil uji coba menunjukkan peningkatan kecepatan hingga 3 kali lipat dibandingkan tanpa menerapkan paralelisme. Pada hasil uji coba, juga didapatkan dua jenis parameter yang masing-masing memiliki karakteristik tersendiri (6= cepat, 12= kualitas baik).
\end{abstract}

Kata Kunci-Ray Tracing, Rendering, Agglomerative Clustering, Grafika, BVH.

\section{PENDAHULUAN}

$\mathrm{D}$ IANTARA banyak metode advanced rendering, Ray Tracing merupakan salah satu metode yang intuitif dan mudah diterapkan. Salah satu kelemahan Ray Tracing terletak pada proses tracing di mana setiap ray yang ditembakkan harus dicek persilangannya dengan seluruh objek. Proses tersebut memakan $75 \%$ waktu keseluruhan proses [1]. Salah satu solusi masalah tersebut adalah dengan membangun Bounding Volume Hierarchy (BVH). BVH adalah sebuah struktur data berupa tree yang setiap node-nya adalah sebuah container yang melingkupi beberapa container lain atau sebuah poligon (Gambar 1) [2].

Pembangunan BVH secara otomatis dapat dilakukan dengan melakukan clustering terhadap sejumlah container yang berisi sebuah poligon [3] [4]. Penggunaan Naive Agglomerative Clustering pada pembentukan BVH tidak feasible karena Agglomerative Clustering dapat memberikan kompleksitas $\mathrm{O}\left(\mathrm{N}^{2}\right)$ atau lebih buruk. Dengan optimalisasi yang tepat dan dengan memanfaatkan paralelisme, kita dapat membangun BVH menggunakan Agglomerative Clustring.

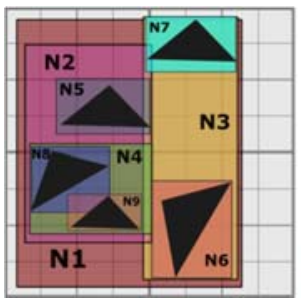

(a)

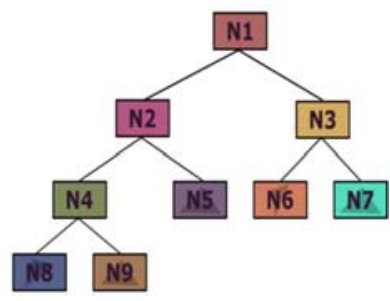

(b)
Gambar 1. Ilustrasi BVH pada bidang 2 dimensi (a) dan representasi tree-nya (b)

\section{RAY TRACING DENGAN BVH}

Pada algoritma Ray Tracing, kita memerlukan perhitungan persilangan ray-object sebanyak jumlah objek per pixel. BVH tersusun dari container dalam bentuk 3 dimensi yang membentuk sebuah tree. Dengan memanfaatkan BVH, objek yang parent-nya tidak bersilangan dengan objek tidak perlu diperhitungkan persilangannya (ditunjukkan pada Gambar 2). Pada penelitian kali ini diimplementasikan BVH dalam bentuk binary tree. Gambar 1 menunjukkan ilustrasi BVH pada bidang 2 dimensi dan dalam bentuk tree.

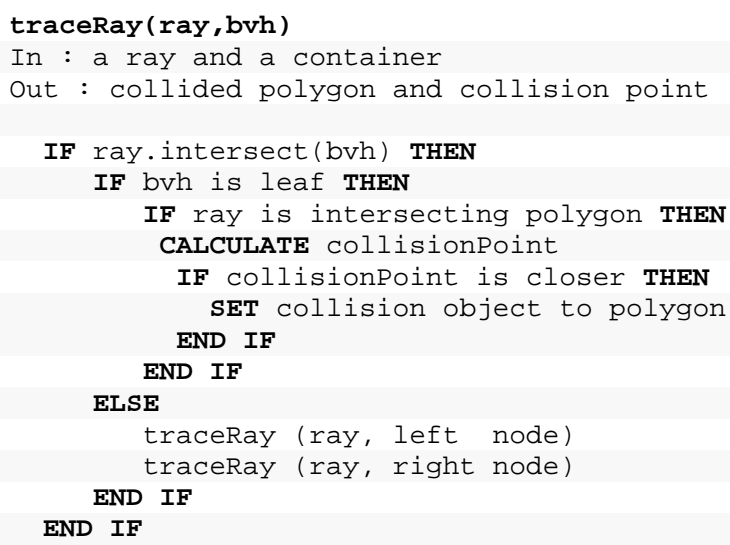

Gambar 2. Pseudocode Ray Tracing dengan BVH

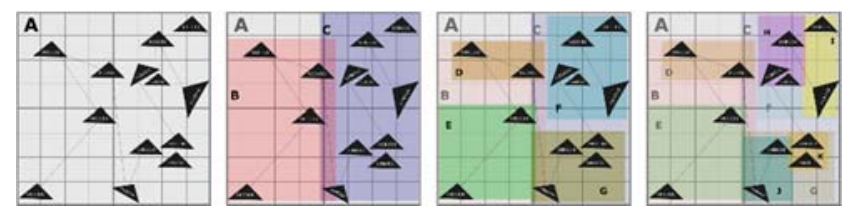

Gambar 3. Tahap downward AAC. Pada tiap iterasi setiap sublist dibagi menjadi dua buah list baru hingga memenuhi threshold 


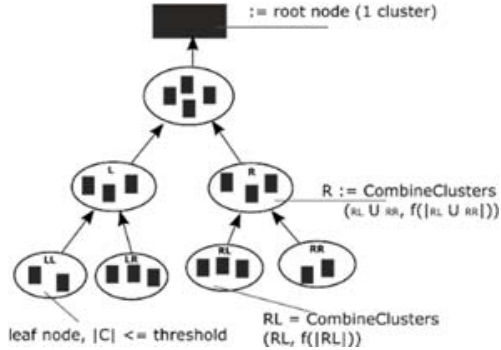

Gambar 4. Tahap upward AAC. tiap kotak mewakili sebuah binary tree. Tiap node cluster mengandung $\mathrm{n}$ tree.

\section{APPROXIMATE AGGLOMERATIVE CLUSTERING}

\section{A. Agglomerative Clustring}

Agglomerative Clustering digunakan dalam berbagai bidang mulai dari data mining, kompresi data, dan lain-lain. Hal ini disebabkan kualitas cluster yang dihasilkan lebih baik jika dibandingkan dengan metode divisive dan pada implementasinya dapat menggunakan fungsi jarak yang sesuai dengan kebutuhan pengguna [3]. Namun, Agglomerative Clustering tanpa optimalisasi dengan kompleksitas $\mathrm{O}\left(\mathrm{N}^{3}\right)$ tidak praktikal.

\section{B. Approximate Agglomerative Clustering}

Pada kesempatan kali ini digunakan Approximate Agglomerative Clustering sebagai metode untuk membangun BVH. Secara garis besar AAC adalah Agglomerative Clustering dengan tahapan preprocessing yang membagi list cluster menjadi beberapa sub-list hingga perhitungan jarak tidak dilakukan secara global [4].

Fitur utama dari AAC adalah pembagian subset (tahap downward - Gambar 3) di mana sebuah node hanya perlu mencari tetangga terdekat dari subset tersebut [4]. Dengan node yang sudah tersortir, pembagian subset dapat dilakukan dengan cepat dan tidak akan mengurangi kualitas cluster secara signifikan. Sub-list tersebut lalu di satukan dengan menggunakan Agglomerative Clustering (tahap upward Gambar 4).

Tahapan pertama AAC adalah tahap preprocessing data poligon. Proses yang dilakukan adalah menghitung Morton Code masing-masing poligon dan melakukan sorting dengan Radix Sort yang dijalankan pada awal buildBVH (Gambar 5). Morton Code digunakan untuk memudahkan proses sorting dengan menjaga lokalitas data. Radix Sort digunakan karena cocok digunakan untuk tipe data Morton Code.

Setelah tahapan preprocessing, cluster akan dibentuk pada metode buildTree (Gambar 6) yang akan menghasilkan cluster sesuai parameter algoritma. Proses ini akan membagi list poligon secara rekursif hingga memenuhi threshold tertentu. Tahap pembagian list memanfaatkan Morton Code sehingga hanya perlu mencari perubahan bit di posisi tertentu. Dikarenakan Morton Code menjaga locality data, hasil pembagian list tidak akan merusak kualitas tree.

Setelah jumlah node dalam suatu subset memenuhi kriteria, akan dilakukan Agglomerative Clustering dengan metode combineClusters (Gambar 7) yang merupakan implementasi Agglomerative Clustering dengan optimalisasi memoization. Tahap terakhir adalah menggabungkan seluruh cluster yang tersisa menjadi satu cluster (root). Tahap penggabungan cluster pada BVH bersifat non-decremental sehingga kita dapat menerapkan beberapa optimalisasi seperti menghitung jarak di awal pemanggilan loop dan tidak menghitung ulang jarak kecuali pada node yang membutuhkan. Penelitian kali ini mengimplementasikan algoritma AAC yang diterapkan oleh G. Yan, H. Yong, et al. [4].

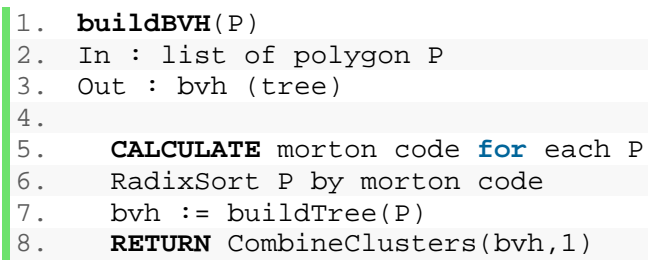

Gambar 5. Pseudocode buildBVH.

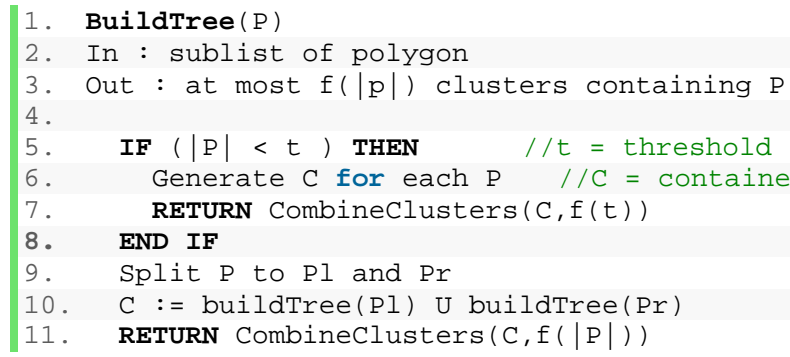

Gambar 6. Pseudocode buildTree.

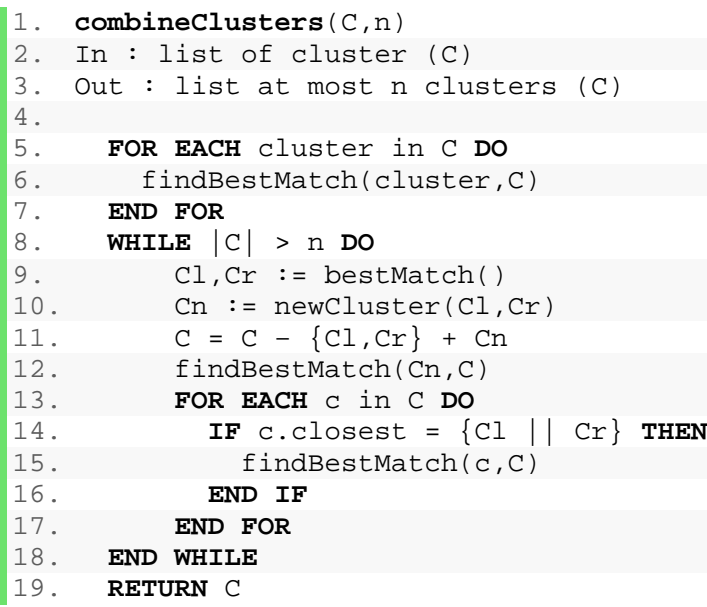

Gambar 7. Pseudocode combineClusters.

\section{Container sebagai Bounding Volume}

Container adalah sebuah bangun tiga dimensi yang melingkupi objek lain (container lain atau poligon) dengan volume sekecil mungkin. Container digunakan sebagai node pada tree yang akan dibangun. Pada penelitian kali ini ditepkan dua jenis container yaitu box dan sphere.

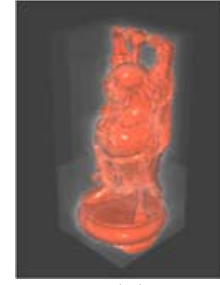

(a)

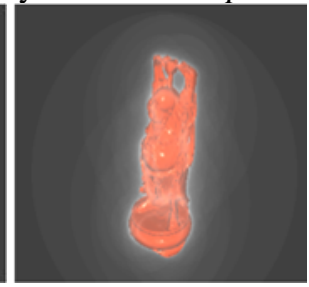

(b)
Gambar 8. Visualisasi BVH pada model "Buddha" [5] dengan box container (a) dan sphere container (b) 
Implementasi container jenis box menggunakan konsep Axis Aligned Bounding Box (AABB) [3]. Karakteristik AABB adalah tiap sisinya paralel pada salah satu sisi yang dibentuk dari dua sumbu pada sistem koordinat. AABB dapat direpresentasikan dengan dua buah titik yaitu titik terjauh dan terdekat terhadap origin pada sistem koordinat. Countainer jenis sphere dibangun dengan membentuk lingkaran yang melingkupi bangun segitiga lalu membentuk bola berdasarkan lingkaran tersebut.

\section{Morton Code dan Radix Sort}

Morton Code (disebut juga dengan z-ordering) adalah salah satu cara merepresentasikan posisi titik pada n-dimensi menjadi 1 dimensi. Morton Code digunakan oleh Gargantini [6] sebagai metode untuk merepresentasikan node pada quad tree pada pembagian scene secara spasial.

Morton Code memudahkan perhitungan fungsi jarak antar dua titik pada dimensi lebih dari satu karena menjaga lokalitas tiap dimensi dan memudahkan sorting data. Morton Code juga sering digunakan dalam pembentukan BVH. Pada implementasi kali ini Morton Code hanya digunakan sebagai pemisah dalam satu set node pada tahap downward AAC [4].

Radix Sort adalah metode sorting yang secara iterasi mengurutkan tiap digit dari elemen yang ingin diurutkan. Radix Sort juga merupakan algoritma sorting dengan stabilitas yang baik dengan kompleksitas linear. Dengan kondisi input tertentu, Radix Sort lebih efisien dari metode sorting umum seperti Quick Sort. Radix Sort juga mudah diparalelkan sehingga dapat di optimalisasi bersamaan dengan metode lain pada penelitian ini.

\section{HASIL UJI COBA DAN ANALISIS}

Dalam penelitian ini dilakukan serangkaian uji coba untuk menganalisis beberapa parameter AAC dan pengaruhnya pada performa program secara keseluruhan. Dua parameter yang berhubungan langsung dengan performa program adalah jenis container dan threshold AAC.

\section{Pada}

Tabel 1 dan Tabel 2 terlihat bahwa container jenis box menunjukkan hasil lebih baik jika dibandingkan dengan jenis sphere. Perbandingan waktu pembangunan BVH konsisten pada semua scene. Sphere sebagai bangun tiga dimensi membutuhkan volume lebih besar untuk mencakup objek lain jika dibandingkan dengan box (Gambar 8). Hal ini menyebabkan jumlah persilangan ray-container yang lebih tinggi pada $\mathrm{BVH}$ pada container jenis sphere yang mengurangi efisiensi BVH secara umum.

Pada Gambar 9 terlihat bahwa nilai threshold berbanding lurus dengan kualitas $\mathrm{BVH}$ dan berbanding terbalik dengan kecepatan pembentukan BVH. Nilai threshold yang terlalu tinggi mengurangi efisiensi metode, terlihat nilai 12 memberikan nilai terbaik dan nilai 6 memberikan waktu pembentukan yang cepat. Berdasarkan hasil di atas ditetapkan dua jenis threshold AAC yaitu fast $=6$ dan $H Q=12$.

Secara teori kualitas tree paling baik akan didapatkan dengan nilai threshold yang sama dengan jumlah poligon (Naive Agglometarive Clustering) namun waktu pembentukan yang lama membuat pendekatan tersebut tidak feasible. Kualitas tree juga dapat ditinjau dari jumlah pemanggilan fungsi intersection pada tiap pixel. Gambar 10 menunjukkan peningkatan kualitas tree yang berbanding lurus dengan nilai threshold. Pada Ray Tracing tanpa BVH, jumlah pemanggilan fungsi intersection akan konstan yaitu sesuai jumlah poligon, dari Gambar 10 dapat disimpulkan bahwa BVH dapat mengurangi kompleksitas Ray Tracing secara signifikan.

Tabel 1. Kecepatan berdasarkan jenis container BVH.

\begin{tabular}{lcccccc}
\hline \multirow{2}{*}{ scene } & \multicolumn{3}{c}{ box } & \multicolumn{3}{c}{ sphere } \\
\cline { 2 - 7 } & build* $^{*}$ & trace** & $\begin{array}{c}\text { avg. } \\
\text { intersects } \\
\text { test } * * *\end{array}$ & build* & trace** & $\begin{array}{c}\text { avg. } \\
\text { intersects } \\
\text { test *** }\end{array}$ \\
\hline teapot & 92 & 626 & 19 & 126 & 3985 & 49 \\
\hline sponza & 815 & 3373 & 119 & 1083 & 32462 & 430 \\
\hline car & 1839 & 1526 & 42 & 2348 & 11418 & 114 \\
\hline conference & 2904 & 2915 & 114 & 3634 & 51966 & 706 \\
Buddha & 4425 & 497 & 15 & 5774 & 2339 & 34 \\
\hline dragon & 7807 & 5042 & 101 & 9824 & 30999 & 228 \\
\hline \hline
\end{tabular}

* BVH build time (ms)

** scene tracing time (ms)

*** average ray-bin or ray-obj intersect function called per ray

Tabel 2. Rasio kecepatan (BOX : SPHERE).

\begin{tabular}{clccc}
\hline \hline & & \multicolumn{3}{c}{ Ratio (box : sphere) } \\
\cline { 3 - 5 } No & scene & build * & trace ** & $\begin{array}{c}\text { avg. } \\
\text { intersects } \\
\text { test *** }\end{array}$ \\
\hline 1 & teapot & 0,73 & 0,16 & 0,38 \\
2 & sponza & 0,75 & 0,10 & 0,28 \\
3 & car & 0,78 & 0,13 & 0,37 \\
4 & conference & 0,80 & 0,06 & 0,16 \\
5 & Buddha & 0,77 & 0,21 & 0,45 \\
6 & dragon & 0,79 & 0,16 & 0,44 \\
\hline & Average & 0,77 & 0,14 \\
\hline \hline
\end{tabular}

* BVH build time (ms)

** scene tracing time (ms)

*** average ray-bin or ray-obj intersect function called per ray
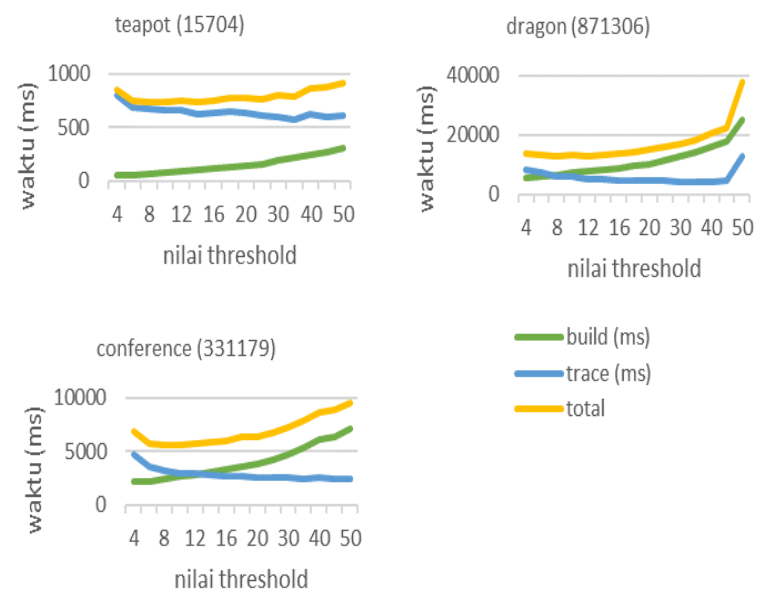

—build (ms)

- $\operatorname{trace}(\mathrm{ms})$ - total

Gambar 9. Pengaruh threshold pada kecepatan konstruksi dan rendering pada tiga scene yang berbeda. 


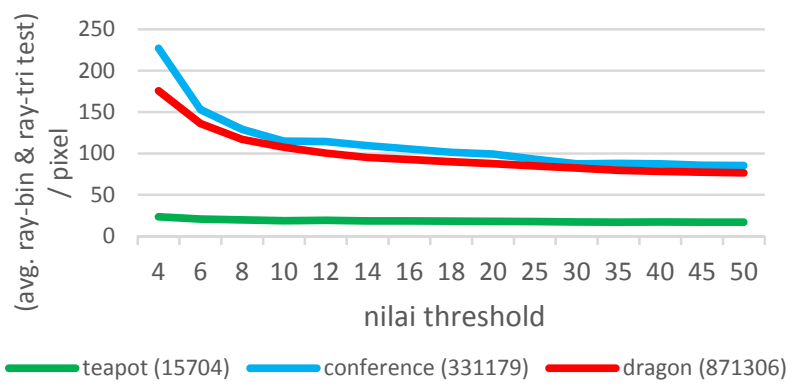

Gambar 10. Rerata jumlah intersection test tiap pixel pada uji coba threshold pada tiap scene

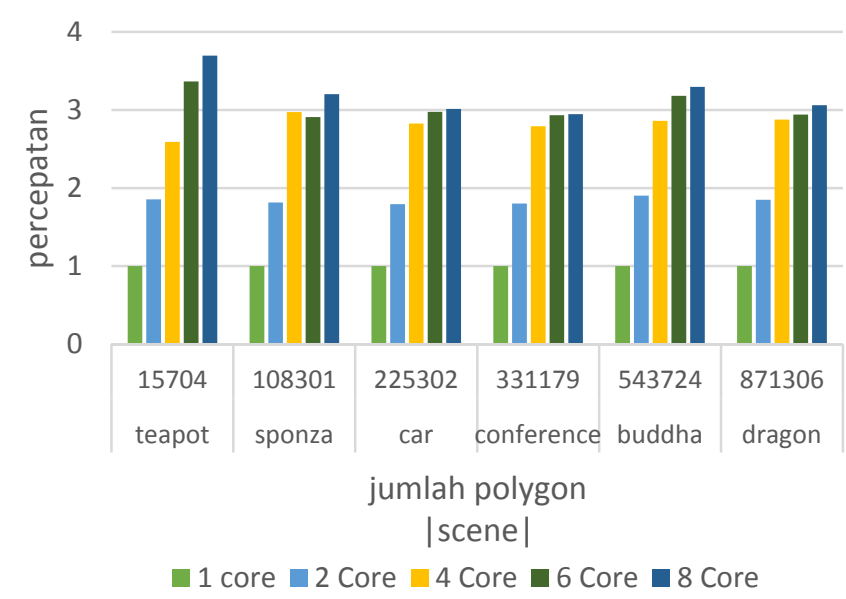

Gambar 11. Percepatan konstruksi BVH berdasarkan jumlah core, nilai tinggi lebih baik.

Hasil uji coba pada Gambar 11 menunjukkan peningkatan kecepatan yang signifikan pada perubahan jumlah core. Dikarenakan keterbatasan perangkat uji coba, tidak dapat ditentukan berapa besar peningkatan kecepatan pada jumlah core yang lebih besar. Berdasarkan hasil uji coba, penggunaan delapan core $^{1}$ menghasilkan peningkatan kecepatan lebih dari tiga kali lipat jika dibandingkan dengan satu core. Peningkatan kecepatan ini konsisten pada seluruh scene dengan jumlah poligon yang bervariasi.

\section{KESIMPULAN}

Ray Tracing sebagai metode rendering realistis sangat terbantu oleh struktur data Bounding Volume Hierarchy. Pembentukan BVH dengan Approximate Agglomerative Clustering adalah metode yang feasible dan seluruh proses tersebut sangat efektif jika diterapkan secara paralel. Dari hasil uji coba juga dapat disimpulkan bahwa jenis container box lebih baik dari pada sphere dan threshold AAC optimal adalah 6 (fast) dan 12 (high quality).

Proses-proses yang menerapkan paralelisme akan meningkat performanya jika diterapkan pada (Graphical Processing Unit) GPU. Hal ini dikarenakan GPU sebagai unit dengan jumlah core yang besar dapat menjalankan banyak proses secara paralel dengan efisien.

\section{REFERENCES}

[1] T. Whitted, “An improved illumination model for shaded display,” $A C M$ SIGGRAPH Computer Graphics, vol. 13, no. 2, p. 14, 1979.

[2] J. Goldsmith dan J. Salmon, "Automatic Creation of Object Hierarchies for Ray Tracing,” Computer Graphics and Applications, vol. 7, no. 5, pp. 14-20, 1987.

[3] B. Walter, K. Bala, M. Kulkarni dan K. Pingali, "Fast agglomerative clustering for rendering," IEEE Symposium on Interactive Ray Tracing 2008, pp. 81-86, 2008.

[4] G. Yan, H. Yong, K. Fatahalian and G. Blelloch, "Efficient BVH construction via approximate agglomerative clustering," Proceedings of the 5th High-Performance Graphics Conference, pp. 81-88, 2013.

[5] M. McGuire, “Computer Graphics Archive,” August 2011. [Online]. Available: http://graphics.cs.williams.edu/data.

[6] I. Gargantini, "An effective way to represent quadtrees," Communication of the ACM, vol. 25, pp. 905-910, 1982. 